\title{
Mitigating plasmonic absorption losses at rear electrodes in high-efficiency silicon solar cells using dopant-free contact stacks
}

Sihua Zhong,,${ }^{1,2}{ }^{*}$ Julie Dreon, ${ }^{1}$ Quentin Jeangros, ${ }^{1}$ Erkan Aydin, ${ }^{3}$ Stefaan De Wolf, ${ }^{3}$ Fan Fu, ${ }^{1}$ Mathieu Boccard, ${ }^{1, *}$ and Christophe Ballif ${ }^{1}$

1 Photovoltaics and Thin-Film Electronics Laboratory (PV-lab), Institute of Microengineering (IMT), École Polytechnique Fédérale de Lausanne (EPFL), Rue de la Maladière 71b, CH-2002 Neuchâtel, Switzerland.

2. Institute of Solar Energy and Key Laboratory of Artificial Structures and Quantum Control (Ministry of Education), School of Physics and Astronomy, Shanghai Jiao Tong University, Shanghai 200240, P. R. China.

3. KAUST Solar Center (KSC), King Abdullah University of Science and Technology (KAUST), Thuwal 23955-6900, Kingdom of Saudi Arabia.

*Corresponding author: sihua.zhong@epfl.ch, mathieu.bocarrd@epfl.ch

\begin{abstract}
:
In conventional crystalline silicon (c-Si) solar cells, charge-carrier selectivity is usually realized by doping Si. Although this strategy yields good carrier selectivity, the presence of dopants imposes inherent performance limitations due to parasitic absorption and carrier recombination. The development of alternative carrier-selective contacts, using non-Si electron and hole transport layers (ETLs and HTLs, respectively), has the potential to overcome such drawbacks and simultaneously reduce the cost and/or simplify the fabrication process of c-Si solar cells. Nevertheless, devices relying on such non-Si contacts with power conversion efficiencies (PCEs) that rival their classical counterparts are yet to be demonstrated. In this study, we bring forward one key element towards this demonstration by incorporating low-pressure chemical vapor deposited $\mathrm{ZnO}$ as ETL in c-Si solar cells. Such layer negligibly absorbs infrared light due to its low carrier density. Placed at the rear of the device, we find that rather thick $(75 \mathrm{~nm})$ $\mathrm{ZnO}$, capped with $\mathrm{LiF}_{\mathrm{x}} / \mathrm{Al}$ simultaneously enables efficient electron selectivity and suppression of parasitic infrared absorption. Next, we integrate these electron-selective contacts in c-Si solar cells with $\mathrm{MoO}_{\mathrm{x}}$-based hole-collecting contacts at the device front to realize full-area dopantfree-contact solar cells. In our proof-of-concept device, we demonstrate a PCE as high as $21.4 \%$, which is a record for this novel device class and is at the level of conventional industrial solar cells.
\end{abstract}




\section{Broader context:}

Thanks to continuous technological progress, the electricity-generation cost by crystalline silicon (c-Si) photovoltaics has become competitive compared to conventional electricity generation in a steadily increasing number of locations throughout the world. However, to ensure the multiple terawatt generation of photovoltaic electricity, needed to meet globally targetted climate goals, further cost decreases are strongly needed, which then will also allow additional expenses for electricity management through storage or curtailment. This can be done either through power conversion efficiency improvements or through production cost reductions. Although industrial c-Si solar cell technology maintains a fast pace at improving its perfomance, its reliance on heavily doped silicon regions as carrier-selective layers inevitably results in carrier-recombination and light absorption losses. This limits the power output of these devices, unless highly localized electrical contacts are implemented which, in turn, demand sophisticated processing. In recent years, so-called dopant-free c-Si solar cells have been proposed to overcome this issue, by utilizing wider bandgap materials such as metal oxides and metal nitrides to replace doped Si as charge-carrier selective layers. In this study, we show how to achieve such dopant-free contacts with simple, scalable fabrication methods and materials. In particular, we present for the first time how ZnO-based contacts can simultaneously realize efficient electron selectivity and mitigation of parasitic plasmonic light absorption at the rear side of solar cells. This study paves the road to further development of high-efficiency c-Si solar cells with radically simpler fabrication methods compared to the industrial state-of-the-art. Moreover, our contact design may also inspire the design of efficient carrier-selective contacts with an excellent optical performance for other optoelectronic devices, such as perovskite solar cells. 


\section{Introduction}

Efficient carrier-selective contacts aim at realizing effective separation and collection of photo-generated charge carriers without incurring recombination losses, and are key components to achieve high-efficiency solar cells. In conventional crystalline $\mathrm{Si}$ (c-Si) solar cells, carrier-selectivity, along with ohmic-contact formation, is accomplished by heavy doping. ${ }^{1}$ At the front-side of the device, this is usually accomplished through dopant diffusion into the c-Si wafer, requiring a high thermal budget $\left(>800{ }^{\circ} \mathrm{C}\right) .{ }^{2}$ At the rear side, to lower surface-recombination losses, commercial devices increasingly feature a so-called passivated emitter and rear cell (PERC) structure. This contact consists of a passivating dielectric layer that features holes through which metal electrodes locally contact heavily doped regions. ${ }^{3}$ However, despite such process sophistication, these devices still suffer from recombination at their contacts. Moreover, the heavily doped regions also induce optical losses due to free-carrier absorption of infrared light. ${ }^{4}$ In recent years, a considerable research effort has been devoted to the development of so-called 'passivating contact' technologies, of which silicon heterojunction solar cells and poly-Si contacted solar cells are prominent examples. ${ }^{5,6}$ Externally to the wafer, both technologies employ thin doped Si layers, overlying thin buffer layers, to accomplish excellent carrier-selectivity with high levels of surface passivation, respectively. Using such contacts leads to simple one-dimensional carrier transport and also suppresses Auger recombination in c-Si, as heavy doping inside the wafer can be avoided. The implementation of such contacts has resulted in devices with outstanding open-circuit voltages $\left(V_{\mathrm{OC}}\right)$. However, the use of thin, doped silicon layers may still result in some optical losses, especially in the blue part of the solar spectrum when placed at the sunward side due to their limited bandgap, ${ }^{7}$ and in its red part where both front and back layers can result in parasitic free-carrier absorption. In addition, these passivating-contact technologies may require capital-intensive equipment for layer deposition.

These drawbacks have stimulated the development of devices featuring alternative carrierselective materials such as metal oxides, ${ }^{8-10}$ nitrides, ${ }^{11,12}$ fluorides, ${ }^{13,14}$ and organic materials. ${ }^{15}$ Functional contact stacks relying on such electron and hole transport layers (ETLs and HTLs, respectively) are therefore often referred to as "dopant-free" contacts, although the real attractive feature is that these contacts are free of any heavily doped Si region (internal or external to the wafer), resulting in a high optical transparency. Indeed, the optical properties of these novel carrier-selective materials can be tailored to reduce the parasitic absorption compared to doped $\mathrm{Si}$, both in the blue part of the spectrum by using wider bandgap materials, 
as well in its red part by using dopant-free (or lowly doped) materials that minimize free-carrier absorption losses. Moreover, their fabrication methods are generally simple and only require a low processing temperature $\left(<200{ }^{\circ} \mathrm{C}\right)$. As HTLs, organic semiconductor materials such as PEDOT:PSS, ${ }^{15}$ as well as metal oxides (particularly $\mathrm{MoO}_{\mathrm{x}},{ }^{8,16-18} \mathrm{NiO}_{\mathrm{x}},{ }^{19} \mathrm{WO}_{\mathrm{x}},{ }^{17,20} \mathrm{~V}_{2} \mathrm{O}_{\mathrm{x}},{ }^{21}$ ), are at present extensively explored. For example, our research group has successfully demonstrated efficient hole selectivity of $\mathrm{MoO}_{\mathrm{x}}$, to replace $p$-type hydrogenated amorphous silicon $[\mathrm{a}-\mathrm{Si}: \mathrm{H}(\mathrm{p})]$ in silicon heterojunction solar cells. ${ }^{8}$ Notably, $\mathrm{MoO}_{\mathrm{x}}$ has a lower parasitic absorption for short wavelengths due to its higher bandgap. Therefore, solar cells using $\mathrm{MoO}_{\mathrm{x}}$ as HTL at the sunward side exhibit a higher short-circuit current density $\left(J_{\mathrm{SC}}\right){ }^{22}$ As ETLs, $\mathrm{LiF}_{\mathrm{x}},{ }^{14,23} \mathrm{MgO}_{\mathrm{x}},{ }^{9,24} \mathrm{MgF}_{\mathrm{x}},{ }^{13} \mathrm{TiO}_{\mathrm{x}},{ }^{10,25,26} \mathrm{TaO}_{\mathrm{x}},{ }^{27} \mathrm{TaN}_{\mathrm{x}},{ }^{11}$ or alkali/alkaline-earth metal carbonates, ${ }^{28}$ combined with a low-work-function metal such as $\mathrm{Al}, \mathrm{Mg}$ and $\mathrm{Ca}$ have been demonstrated to yield efficient electron-selective contacts in c-Si solar cells. Generally, these contacts are placed at the rear side of solar cells. Nevertheless, in all these cases the thickness of the ETLs is limited to a few nanometers to ensure efficient electron selectivity, which inevitably incurs severe parasitic infrared light absorption in the metal due to the excitation of surface plasmon polaritons. ${ }^{29}$ Thus, all dopant-free passivating-contact strategies unveiled so far for electron extraction actually have inferior optical performance compared to their siliconbased counterparts, such as silicon heterojunction solar cells. Therefore, following the demonstration of the optical gains in the blue part of the spectrum by using materials such as $\mathrm{MoO}_{\mathrm{x}}$ as HTL, it is widely accepted that solving the parasitic light absorption issue within the electron-selective contact at the rear is at present one of the most important aspects to further enhance the efficiency of dopant-free carrier-selective solar cells. This will be even more important for their future application in tandem solar cells.

To mitigate plasmonic absorption losses at the rear electrode, a rather thick (e.g., >50 nm) ETL or transparent electrode with a low refractive index should be inserted between the silicon and metal, without sacrificing the electron selectivity. Moreover, as stated, this film should have a low carrier density to avoid free-carrier absorption. ${ }^{30} \mathrm{We}$ have previously reported that conductive $\mathrm{ZnO}: \mathrm{Al}$ capped with $\mathrm{Al}$ can effectively act as an electron-selective contact in silicon solar cells, but unfortunately its optimal thickness is found to be limited to $2 \mathrm{~nm}$ to ensure good electron selectivity, which fails to solve the infrared light absorption problem. ${ }^{31}$ In this study, for the first time, we demonstrate an ETL that simultaneously combines good electronselectivity and greatly reduces parasitic light absorption in the infrared wavelengths without the need for any additional transparent electrode such as indium tin oxide (ITO). The key points to 
construct this structure are the use of (i) a rather thick (several tens of nanometer) $\mathrm{ZnO}$ with a low carrier density, but without obstructing the electron flow, (ii) an Al capping metal and (iii) thin $\mathrm{LiF}_{\mathrm{x}}$ as an interfacial layer between them. Through combining such optically beneficial and electrically efficient electron-selective contact with $\mathrm{MoO}_{\mathrm{x}}$ as HTL in a single solar cell, and using intrinsic a-Si:H [a-Si:H(i)] film as passivation layers on both device sides, a power conversion efficiency (PCE) of $21.4 \%$ is reached. This value is the record PCE for such twoside dopant-free-contact solar cells and is on the level of conventional industrial solar cells. ${ }^{2}$ Notably, in addition to substituting for the $n$-type a-Si:H layer, this strategy allows to use inexpensive $\mathrm{ZnO}, \mathrm{LiF}_{\mathrm{x}}$ and $\mathrm{Al}$ as replacement of the typical ITO / Ag stack. Overall, our strategy paves the road towards simple-processed high-efficiency devices with dopant-free contacts.

\section{Results and discussion}
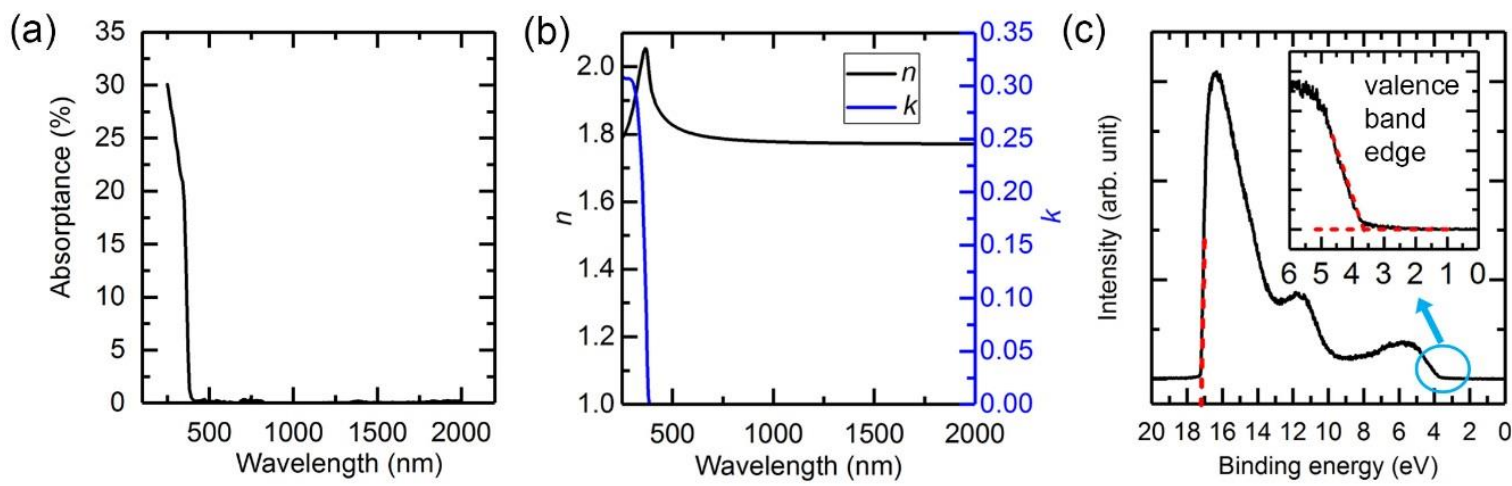

(d)

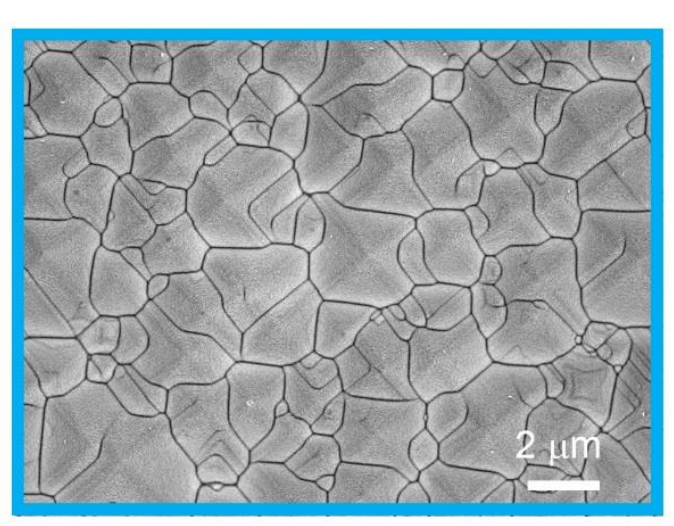

(e)

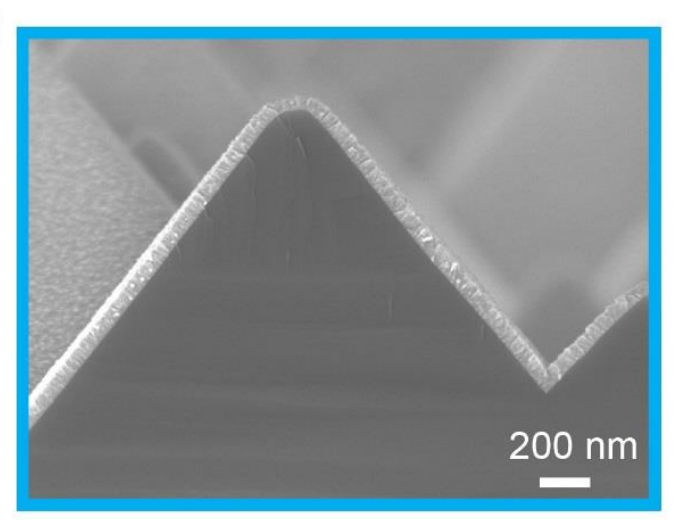

Fig. 1. (a) Optical absorptance of LPCVD ZnO film (thickness: $30 \mathrm{~nm}$ ) as a function of wavelength. (b) Refractive index $(n)$ and extinction coefficient ( $k$ ) of $\mathrm{ZnO}$ measured by spectroscopic ellipsometry. (c) UPS spectrum of the $\mathrm{ZnO}$ film. The red dashed lines show the extrapolation of secondary cut-off point and the inset is the zoomed-in UPS spectrum around the valence band edge. (d) Top-view and (e) crosssectional SEM of the ZnO film deposited on top of the pyramids-textured silicon surface. 
Fig. 1(a) shows the optical absorptance of the $\mathrm{ZnO}$ film grown at a low-temperature $\left(100{ }^{\circ} \mathrm{C}\right)$ by low-pressure chemical vapor deposition (LPCVD). It is of note that this deposition technique is rather simple and suitable for mass production. As can be seen, there is negligible absorption over a broad wavelength range from $500 \mathrm{~nm}$ to $1200 \mathrm{~nm}$. This is confirmed by spectroscopic ellipsometry (SE) measurements, from which the extracted refractive index $(n)$ and extinction coefficient $(k)$ are displayed in Fig. 1(b). The $k$ value is undetectable over the wavelength range from $500 \mathrm{~nm}$ to $1200 \mathrm{~nm}$, indicating low free-carrier absorption. Indeed, Hall-effect measurements reveal that the carrier concentration of the $\mathrm{ZnO}$ film is only $4.3 \times 10^{16} \mathrm{~cm}^{-3}$, much lower than the usual conductive films. ${ }^{30,32}$ These results indicate that when applying $\mathrm{ZnO}$ as an ETL at the rear side of solar cells, light absorption within this film can effectively be neglected. Furthermore, the relatively low $n$-value (1.8) is beneficial to prevent the evanescent wave from reaching the rear metal, thereby reducing parasitic plasmonic light absorption. ${ }^{33}$ From the SE result, the bandgap is extracted to be $3.4 \mathrm{eV}$, being in good agreement with the value obtained from the Tauc-plot of the optical absorption curve (see Fig. S1). The $\mathrm{ZnO}$ film is also characterized by ultraviolet photoelectron spectroscopy (UPS), as shown in Fig. 1(c). The valence band position is estimated to be $7.6 \mathrm{eV}$ using the calculation method discussed elsewhere. ${ }^{34}$ The conduction band position of $4.2 \mathrm{eV}$ is obtained by subtracting the bandgap value from the valence band position. From this, it is concluded that the conduction band position of the LPCVD ZnO is situated just below that of c-Si $(4.05 \mathrm{eV})$, which is beneficial for electron extraction. Conversely, there is a large valence band offset between the $\mathrm{ZnO}$ and the c-Si (valence band of c-Si is at about $5.17 \mathrm{eV}$ ), desirably blocking hole transport from c-Si to $\mathrm{ZnO}$. These results suggest that the LPCVD $\mathrm{ZnO}$ has excellent properties to act as an efficient electron-selective, hole-blocking layer for c-Si solar cells. The surface morphology of $\mathrm{ZnO}$ on the typical random-pyramidal Si surface texture used in c-Si solar cells is investigated by scanning electron microscope (SEM), as shown in Fig. 1(d) and (e). From the top view image, the $\mathrm{ZnO}$ film appears to have a smooth and uniform morphology. The cross-sectional image further shows that the $\mathrm{ZnO}$ film is conformally deposited on the micron-sized Si pyramids, which is reportedly different for spin-coated $\mathrm{ZnO}$ films. ${ }^{35}$ 
(a)

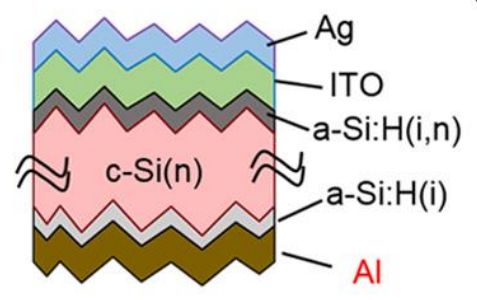

(d)

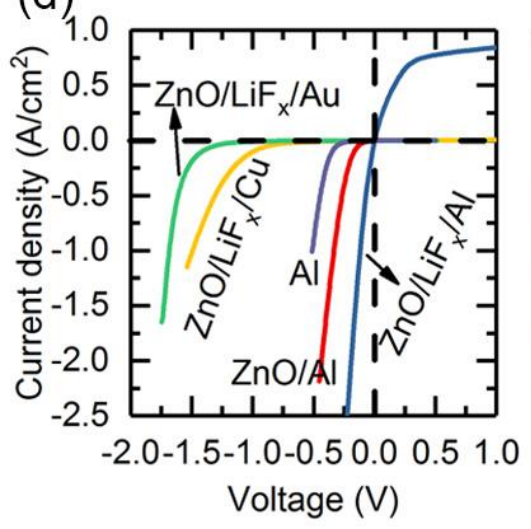

(g)

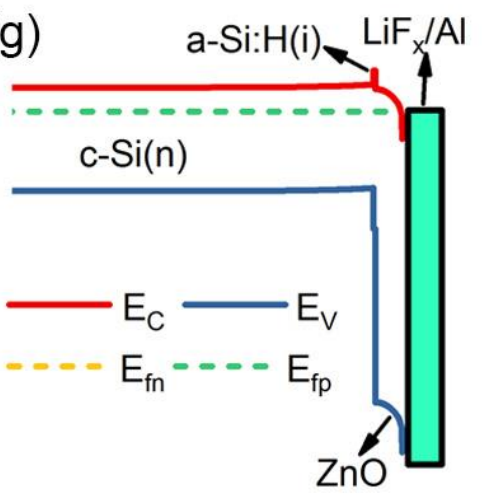

at equilibrium

(b)

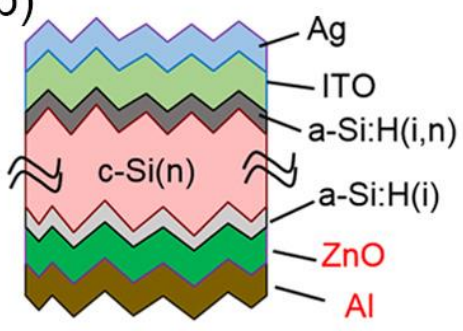

(e)

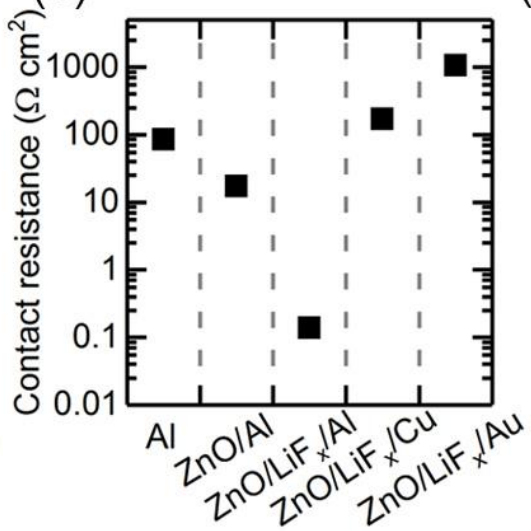

(h)

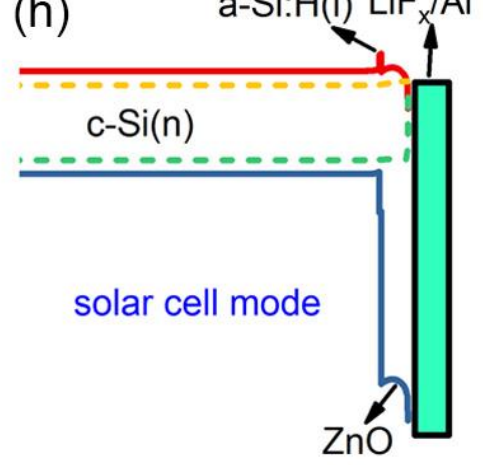

forward bias voltage (c)

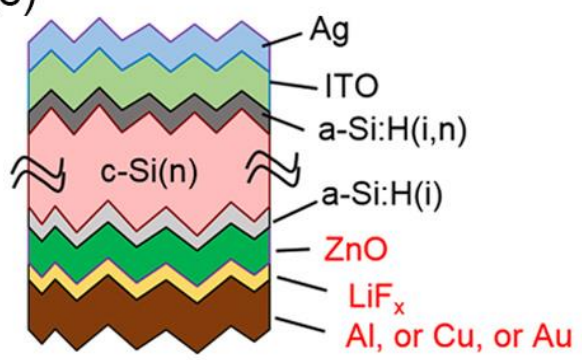

(f)

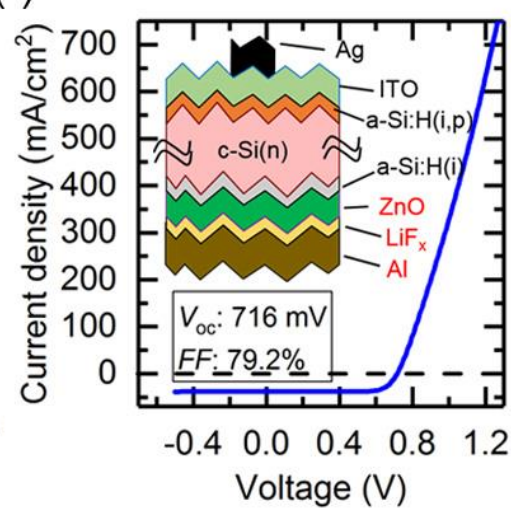

(i)

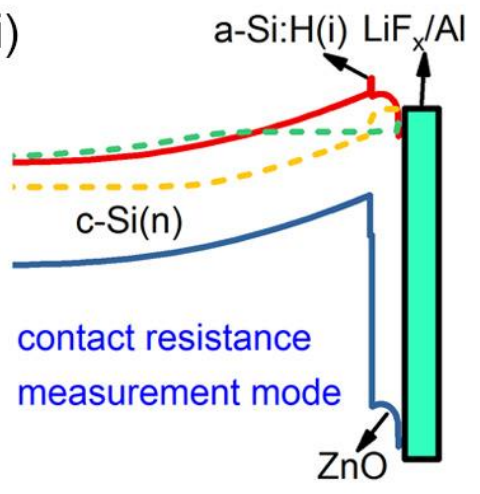

forward bias voltage

Fig. 2. (a-c) Schematics of contact-resistance test structures with different layers at the bottom side: Al (a), $\mathrm{ZnO} / \mathrm{Al}$ (b), $\mathrm{ZnO} / \mathrm{LiF}_{x} /[\mathrm{Al}, \mathrm{Cu}$ or $\mathrm{Au}]$ (c). (d) J-V curves of the different contact resistance measurement samples. (e) Contact resistance of these samples extracted around the origin. (f) $J-V$ curve of the best solar cells, whose electron-selective contact is formed by $\mathrm{ZnO} / \mathrm{LiF}_{x} / \mathrm{Al}$. The inset is a schematic of the cell. (g-i) Possible energy band diagram of the novel electron-selective contact, i.e. $\mathrm{ZnO} / \mathrm{LiF}_{\mathrm{x}} / \mathrm{Al}$, at $(\mathrm{g})$ equilibrium condition $\left(\mathrm{E}_{\mathrm{fn}}\right.$ and $\mathrm{E}_{\mathrm{fp}}$ are the same), (h) forward bias voltage condition in solar cells mode, and (i) forward bias voltage condition in contact resistance measurement mode. $E_{c}, E_{v}, E_{f n}$ and $E_{f p}$ designate conduction band, valence band, quasi-Fermi level for electrons and quasiFermi level for holes, respectively. 
To demonstrate that LPCVD $\mathrm{ZnO}$ is an efficient ETL for c-Si and to understand its role in the full electron-selective contact stack, different electron-selective contact structures were fabricated for contact-resistance measurements, as shown in Fig. 2(a-c). All the top sides of these 'electron-only' test structures feature contacts with the structure c-Si/a-Si:H(i)/a$\mathrm{Si}: \mathrm{H}(\mathrm{n}) / \mathrm{ITO} / \mathrm{Ag}$, which as contact stack has good Ohmic properties, as shown in Fig. S2. The opposite wafer sides are all passivated by a-Si:H(i) as well, but then respectively capped with $\mathrm{Al}$ only, with $\mathrm{ZnO} / \mathrm{Al}$, or with $\mathrm{ZnO} / \mathrm{LiF}_{\mathrm{x}} /$ metal (the metal being varied between $\mathrm{Al}, \mathrm{Cu}$, and $\mathrm{Au}$ ) as electron-selective contacts. Note that the thickness of $\mathrm{ZnO}$ in all these cases is $75 \mathrm{~nm}$, which is considerably thicker than the typical ETLs employed in previous works as mentioned in the introduction. The thickness of $\mathrm{LiF}_{\mathrm{x}}$ is $1.5 \mathrm{~nm}$. Fig. 2(d) shows the current density-voltage $(J-V)$ characteristics of these samples. All the $J-V$ curves saturate in the forward bias voltage condition (i.e. the positive polarity is at the Ag/ITO side), demonstrating the presence of a Schottky junction. However, their onset voltage and dark current differ, depending on the specific contact architecture. On the one hand, the onset voltage decreases by inserting $\mathrm{ZnO}$ between a-Si:H(i) and $\mathrm{Al}$, and is further decreased by adding $\mathrm{LiF}_{\mathrm{x}}$ between $\mathrm{ZnO}$ and $\mathrm{Al}$, suggesting a decreased barrier height by inserting $\mathrm{ZnO}$ and $\mathrm{LiF}_{\mathrm{x}}$. On the other hand, the onset voltage increases by replacing $\mathrm{Al}$ with a high-work-function metal such as $\mathrm{Cu}$ and $\mathrm{Au}$, which indicates an increasing Schottky barrier height. Based on the $J$ - $V$ curves, contact resistance values at around $V=0 \mathrm{~V}$ are extracted to evaluate the electrical contact performance, as shown in Fig. 2(e). As can be seen, inserting $\mathrm{ZnO}$ and $\mathrm{LiF}_{\mathrm{x}}$ between a-Si:H(i) and $\mathrm{Al}$ leads to a significant decrease in contact resistance. The contact resistance reaches a value as low as 0.136 $\Omega \mathrm{cm}^{2}$. However, replacing Al with a high-workfunction metal results in an extremely high contact resistance. These results suggest that the $\mathrm{ZnO} / \mathrm{LiF}_{\mathrm{x}} / \mathrm{Al}$ stack acts as an efficient electronselective contact. Its electron selectivity depends on the capping metal, despite the fact that the $\mathrm{ZnO}$ is rather thick $(75 \mathrm{~nm})$. This is because the carrier density in $\mathrm{ZnO}$ is low, thus making 75nm-thick $\mathrm{ZnO}$ insufficiently thick to completely screen the capping metal electrically. In this case, a low-workfunction metal is still required to achieve good electron-selective contact.

Based on the above results, we choose $\mathrm{ZnO} / \mathrm{LiF}_{\mathrm{x}} / \mathrm{Al}$ as electron-selective contact stack in the solar cells. Fig. 2(f) shows the solar cell structure and its best $J$ - $V$ performance. Here, we used a-Si:H(p) as HTL; a-Si:H(i) is again employed as a passivation layer on both wafer sides. Excitingly, the $V_{\mathrm{OC}}$ reaches $716 \mathrm{mV}$ and the fill factor $(F F)$ is $79.2 \%$, demonstrating on device level the electron-selective effectiveness of our $\mathrm{ZnO} / \mathrm{LiF}_{\mathrm{x}} / \mathrm{Al}$ contact stack. We note that even without a-Si:H(i) at the rear side, the $F F$ and $V_{\mathrm{OC}}$ still reach $77.6 \%$ and $629 \mathrm{mV}$, respectively, 
as shown in Fig. S3. This result demonstrates the good electron selectivity of $\mathrm{ZnO} / \mathrm{LiF}_{\mathrm{x}} / \mathrm{Al}$ again . Here, the passivation effect of $\mathrm{ZnO}$ is clearly not as good as a-Si:H(i), but sufficient to unpin the Fermi-level and activate the carrier selectivity of the contact stack. Interestingly, although the $J$ - $V$ curve of the contact-resistance-test sample saturates under forward bias voltage, the $J$ $V$ curve of the solar cell does not exhibit any S-shape behavior or saturation behavior at forward bias voltage. Therefore, the $\mathrm{ZnO} / \mathrm{LiF}_{\mathrm{x}} / \mathrm{Al}$ contact appears to perform differently between the contact-resistance measurement mode and solar-cell measurement mode under the same forward bias voltage. We explain such apparent discrepancy with the aid of energy band diagrams in the following.

Based on the above experimental results and the low workfunction of the $\mathrm{LiF}_{\mathrm{x}} / \mathrm{Al}$ bilayer, ${ }^{14}$ Fig. 2(g) sketches the possible energy band alignment between c-Si(n), a-Si:H(i), ZnO and $\mathrm{LiF}_{\mathrm{x}} / \mathrm{Al}$ at thermal equilibrium. A slight upward band bending is present around the interface between c-Si, a-Si:H(i) and $\mathrm{ZnO}$ (too small to be noticeable in the sketch). When applying a forward voltage (within a certain range, e.g., $<1 \mathrm{~V}$ ) to solar cells, because the top side is a p-n junction with a higher built-in potential, most of the applied voltage drops over the p-n junction and only a small voltage drop is seen over the c-Si(n)/a-Si:H(i)/ZnO/LiF $/ \mathrm{Al}$ contact stack. Therefore, the energy band alignment in the electron-selective contact is similar to that at equilibrium, where there is no strong barrier, as shown in Fig. 2(h). Consequently, no S-shaped $J-V$ curve is observed for the solar cell structure. However, when applying a forward voltage to the contact-resistance-test sample, because the top side [c-Si/a-Si:H(i)/a-Si:H(n)/ITO/Ag] is a known good Ohmic contact, the applied voltage will mainly drop over the other contact, namely the bottom side [c-Si(n)/a-Si:H(i)/ZnO/LiF $/ \mathrm{Al}$ ], which shows slight Schottky behavior. As a result, the upward band bending in the $\mathrm{c}-\mathrm{Si}(\mathrm{n})$ near this contact becomes much stronger, as shown in Fig. 2(i), leading to stronger (electron) depletion in the c-Si wafer close to the contact and a saturation behavior in the $J$ - $V$ curve. Thus, depending on the studied device (contactresistance-test structure or actual solar cell), the band bending on the electron-contact side is different, despite applying the same external voltage. A careful analysis of the $J-V$ curves associated with the test-structure is hence required. Nevertheless, the contact resistance extracted around $0 \mathrm{~V}$ (see Fig. 2(e)) can be used to evaluate the contact performance of the c$\mathrm{Si}(\mathrm{n}) / \mathrm{a}-\mathrm{Si}: \mathrm{H}(\mathrm{i}) / \mathrm{ZnO} / \mathrm{LiF}_{\mathrm{x}} / \mathrm{Al}$ stack in solar cells, since the voltage drop in this contact is close to $0 \mathrm{~V}$ under solar cell operation in the active $J-V$ quadrant. We confirmed such a heuristic explanation by numerical simulation (see Fig. S4). From our discussion, we conclude that in the design of novel carrier-selective contacts, it may actually be tolerable that contact structures 
display Schottky behavior, but their contact resistance around $0 \mathrm{~V}$ shold be low. A sufficiently low value (for instance, $<0.2 \Omega \mathrm{cm}^{2}$ ) can enable a rather good $F F(>80 \%)$ in single-junction devices, and an unnoticeable loss in multijunction devices (as they exhibit higher voltage and lower current density under standard operating conditions).
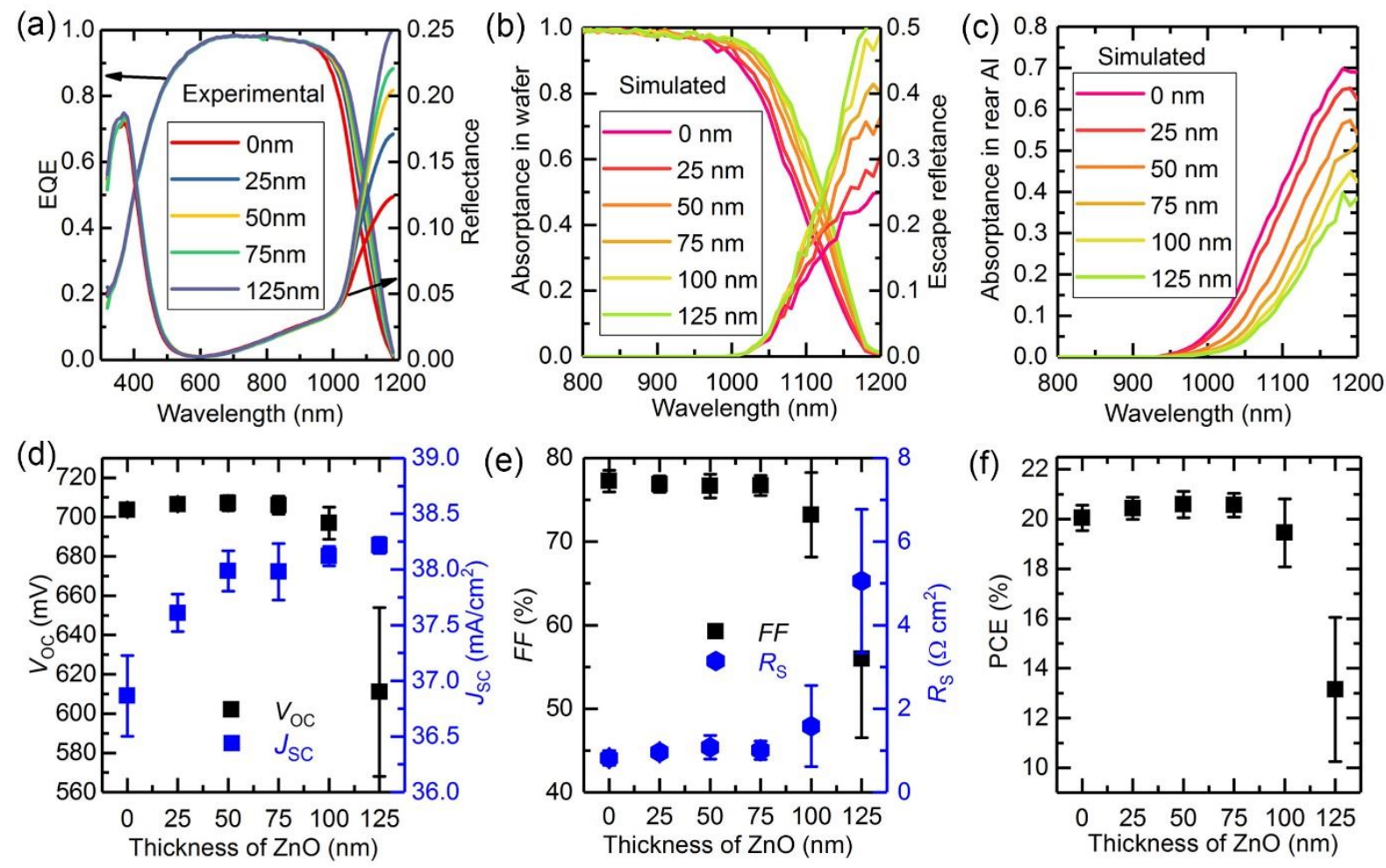

Fig.3. (a) Experimental EQE and reflectance of the solar cells using different-thickness ZnO layers. (b) Simulated absorptance within the Si wafer, internal reflectance and (c) absorptance in the rear Al of the solar cells varying with the thickness of $\mathrm{ZnO}$. (d) $V_{\mathrm{OC}}, J_{\mathrm{SC}}$, (e) $F F, R_{\mathrm{s}}$, and (f) PCE of the solar cells varying with the thickness of $\mathrm{ZnO}$.

After confirming the good electron selectivity of our contact stack, we now turn our attention to the optical performance of the solar cells. Fig. 3(a) shows that both the reflectance and external quantum efficiency (EQE) increase with the $\mathrm{ZnO}$ thickness for wavelengths longer than $1000 \mathrm{~nm}$. To acquire further insight, we carried out optical simulations using a wafer ray tracer, as shown in Fig. 3(b) and (c). The simulated structure is the same as our experimental solar cells (except that the 1.5-nm-thick $\mathrm{LiF}_{\mathrm{x}}$ is not considered for the simulations). Both the simulated absorptance in the wafer and the escape reflectance increase in the infrared wavelength range with increasing the $\mathrm{ZnO}$ thickness, being in accordance with the increase of 
the experimental EQE and reflectance. Note that the escape reflectance is comprised of light that first enters the Si wafer, which is then internally reflected at the rear surface, followed by an escape from the front surface. The experimental reflectance includes the escape reflectance and the external reflectance from the front surface. Fig. 3(c) further shows that the absorptance in the rear $\mathrm{Al}$ decreases with increasing the thickness of $\mathrm{ZnO}$, which is explained by the limited reach of the evanescent wave, and thus the reduced plasmonic absorption loss at the rear $\mathrm{Al}$ electrode. ${ }^{29}$ Therefore, combining experimental and simulation results, we conclude that a thicker $\mathrm{ZnO}$ film is more beneficial for reducing the infrared light absorption in the rear $\mathrm{Al}$ layer and thus more light is reflected back into the Si wafer. This results in both enhanced absorption in the Si wafer and escaped light from the front surface, so the measured EQE and reflectance of solar cells are increased.

As a direct result, $J_{\mathrm{SC}}$ notably increases with increasing the thickness of $\mathrm{ZnO}$ from $0 \mathrm{~nm}$ to $125 \mathrm{~nm}$, as displayed in Fig. 3(d). It is also important to note that despite the increased thickness of $\mathrm{ZnO}$, the $V_{\mathrm{OC}}$ remains almost the same as long as the thickness is below $100 \mathrm{~nm}$; it even shows a slight increase. Fig. 3(e) shows that the series resistance $\left(R_{\mathrm{s}}\right)$ of the solar cells at the maximum power point increases slightly with the $\mathrm{ZnO}$ thickness when the thickness is below $100 \mathrm{~nm}$, and hence there is only a little loss in FF. Consequently, the solar cells using 50-nmthick or 75-nm-thick $\mathrm{ZnO}$ as electron-selective film have the highest average efficiency, as shown in Fig. 3(f). The best solar cell of such a hybrid structure [a-Si:H(p) as HTL, ZnO/LiF $/ \mathrm{Al}$ as electron-selective contact], whose $\mathrm{ZnO}$ thickness is $75 \mathrm{~nm}$, has a PCE as high as $21.6 \%$ with $V_{\mathrm{OC}}=716 \mathrm{mV}, J_{\mathrm{SC}}=38.1 \mathrm{~mA} / \mathrm{cm}^{2}$ and $F F=79.2 \%$. The $J-V$ curve is shown in Fig. 2(f). These results clearly demonstrate that the $J_{\mathrm{SC}}$ can be improved by using a rather thick $\mathrm{ZnO}$ film (compared with most of other reported ETLs, usually of only a few nanometers thin) to reduce the infrared light absorption loss, while good electron selectivity is maintained. Also, this is beneficial for reducing the device fabrication cost, by replacing the rear ITO, commonly used in silicon heterojunction solar cells, with $\mathrm{ZnO}$ to alleviate the infrared-light absorption loss. 
(a)

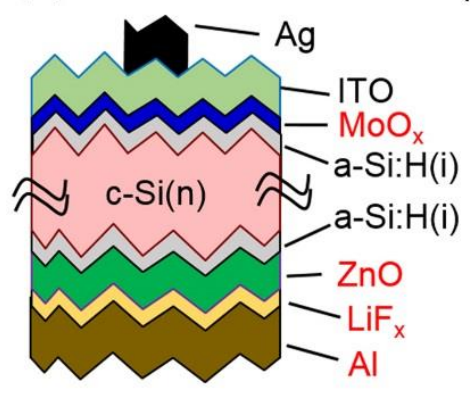

(e)

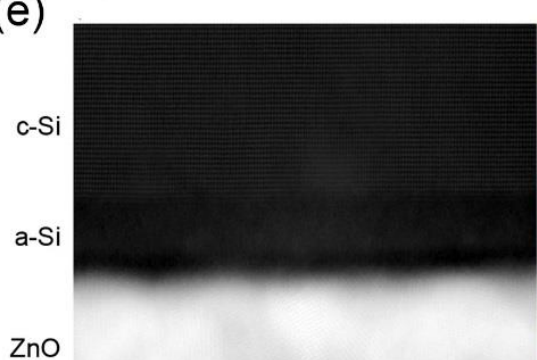

$\mathrm{ZnO}$

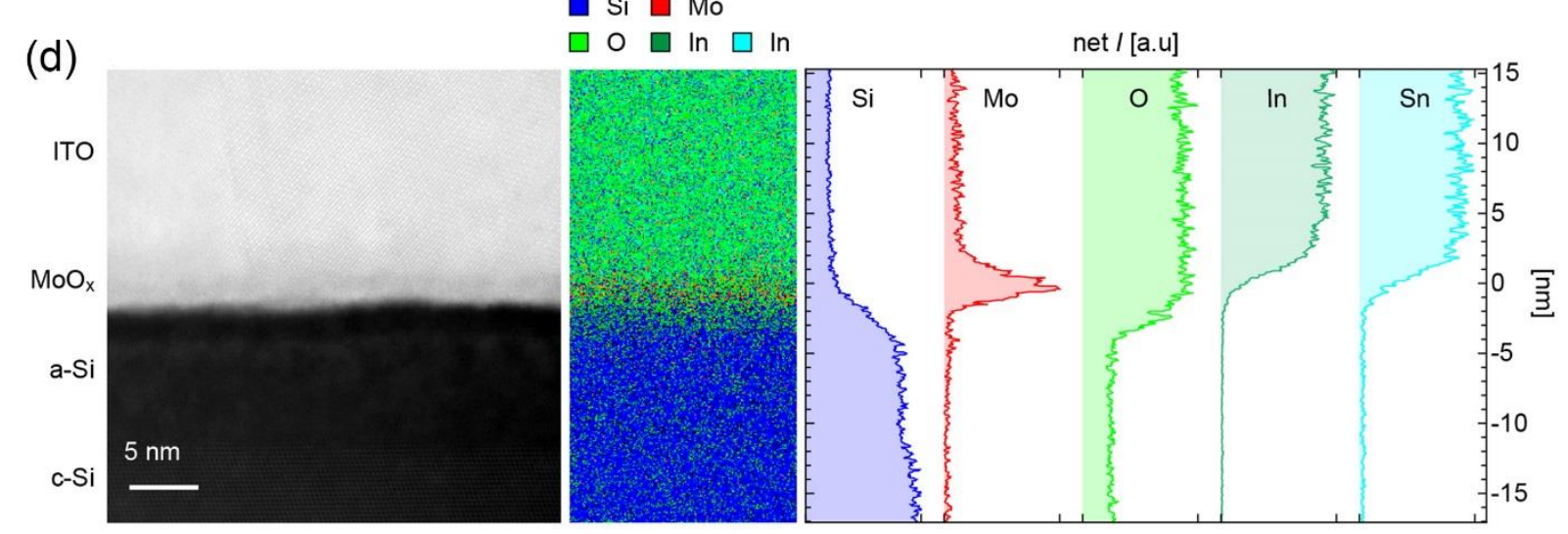

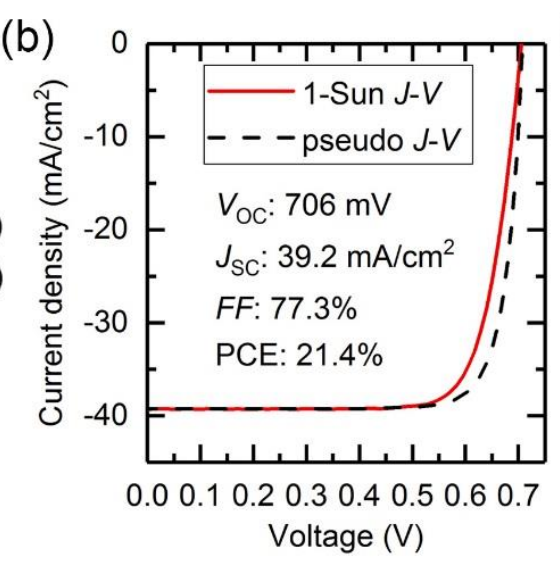

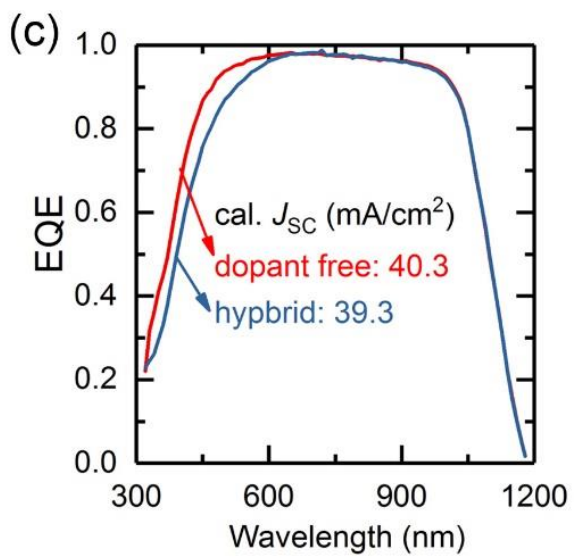

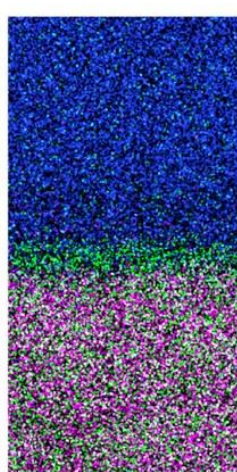

$\square$ Si $\square \mathrm{Zn}$

$\square 0$

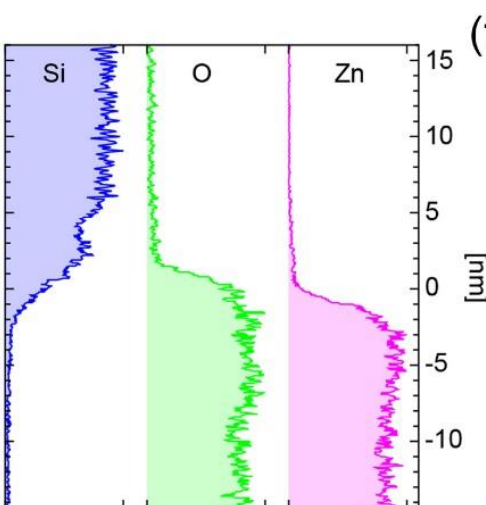

net $/$ [a.u] (f)

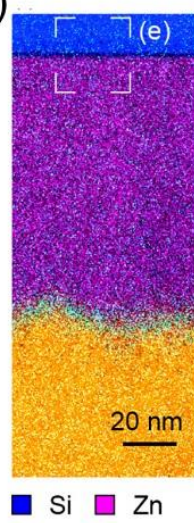

$\square \mathrm{F} \square \mathrm{Al}$

Fig. 4. Schematic of a solar cell with bifacial dopant-free contacts. $\mathrm{MoO}_{\mathrm{x}}$ and $\mathrm{ZnO} / \mathrm{LiF}_{\mathrm{x}} / \mathrm{Al}$ are the holeselective and electron-selective contacts, respectively. (b) 1-Sun J-V curve and pseudo J-V curve of the two-side dopant-free-contact solar cell with an active area of $2 \mathrm{~cm} \times 2 \mathrm{~cm}$. The pseudo $J-V$ is obtained from Suns- $V_{\text {Oc }}$ measurements. (c) EQE spectra of the fully dopant-free-contact solar cell and the hybrid solar cell. The hybrid solar cell features a front side that uses the traditional a-Si:H(p) as hole-selective contact, but the backside is the dopant free contact: $\mathrm{ZnO} / \mathrm{LiF}_{\mathrm{x}} / \mathrm{Al}$. Cal. is short for calculated. (d) Crosssectional STEM HAADF image, EDX map, and corresponding line profile of the hole-selective contact of the solar cell. (e) Cross-sectional STEM HAADF image, EDX map, and corresponding line profile of c- 
$\mathrm{Si} / \mathrm{a}-\mathrm{Si} / \mathrm{ZnO}$ interface. (f) EDX map of the full electron-selective contact of the solar cell, in which the white rectangle indicates the characterization zone for (e).

Following the implementation of our efficient electron-selective contact with low infrared light absorption at the rear side, we replaced the front a-Si:H(p) HTL with $\mathrm{MoO}_{\mathrm{x}}$, thereby forming two-side dopant-free-contact solar cells. Fig. 4(a) shows the schematic diagram of such a solar cell. Here, 4-nm-thick evaporated $\mathrm{MoO}_{\mathrm{x}}$ is used as $\mathrm{HTL}$ and 75-nm $\mathrm{ZnO} / 1.5-\mathrm{nm} \mathrm{LiF}_{\mathrm{x}} / \mathrm{Al}$ as electron selective contact. As observed in Fig. 4(b), its $V_{\mathrm{OC}}, J_{\mathrm{SC}}, F F$ are $706 \mathrm{mV}, 39.2$ $\mathrm{mA} / \mathrm{cm}^{2}$ and $77.3 \%$, respectively. The PCE reaches a value as high as $21.4 \%$, which is the highest value for solar cells with fully dopant-free contacts on both device sides and is $0.7 \%$ (absolute value) higher than the previous record. ${ }^{36}$ The 'pseudo' $J$ - $V$ curve, obtained from Suns$V_{\mathrm{OC}}$ measurements, shows a $V_{\mathrm{OC}}$ of $707 \mathrm{mV}$, similar to the value obtained from the 1-Sun $J-V$ curve. Based on the EQE measurement between Ag grids, the calculated $J_{\mathrm{SC}}$ according to AM $1.5 \mathrm{G}$ spectrum is $40.3 \mathrm{~mA} / \mathrm{cm}^{2}$ [Fig. 4 (c)]. Taking a metal shading fraction of $3 \%$ into account at the device front, the calculated $J_{\mathrm{SC}}$ of the solar cell is $39.1 \mathrm{~mA} / \mathrm{cm}^{2}$, confirming the $J_{\mathrm{SC}}$ value from the 1-Sun $J-V$ measurement. We also show the EQE curve of a hybrid solar cell [a-Si:H(p) and $\mathrm{ZnO} / \mathrm{LiF}_{\mathrm{x}} / \mathrm{Al}$ as $\mathrm{HTL}$ and electron-selective contacts, respectively] in Fig. 4 (c) for comparison. The two-side dopant-free-contact solar cell shows a striking improvement in its short wavelength response compared to the hybrid solar cell because of the higher transparency of $\mathrm{MoO}_{\mathrm{x}}$, compared to a-Si:H(p). ${ }^{8,22}$ Therefore, the rather good $J_{\mathrm{SC}}$ comes now from the combined effects of the improved blue spectrum response due to the use of the thin $\mathrm{MoO}_{\mathrm{x}}$ and the reduced infrared parasitic light absorption owing to the rather thick $\mathrm{ZnO}$ film. We note that $\mathrm{MoO}_{\mathrm{x}}$ and $\mathrm{ZnO}$ have been used as carrier-selective contacts in a single solar cell before, but the PCE was limited to only $16.6 \%$ with $V_{\mathrm{OC}}, J_{\mathrm{SC}}$, and $F F$ values much lower than the ones reported here. ${ }^{37}$ Indeed, one of the key enabling factors in our device is that a high electron selectivity and low optical loss are simultaneously realized by the combination of a thick $\mathrm{ZnO}$ layer in conjunction with $\mathrm{LiF}_{\mathrm{x}} / \mathrm{Al}$, rather than $\mathrm{ZnO} / \mathrm{Ag}$ in the earlier report. ${ }^{37}$

Fig. 4(d-f) show the cross-sectional scanning transmission electron microscopy (STEM) highangle annular dark-field (HAADF) image, energy-dispersive X-ray spectroscopy (EDX) map and corresponding line profile after background subtraction across the hole-selective contact and electron-selective contact of the solar cell, respectively. These data confirm the elemental composition and microstructure of the dopant-free contacts presented here. For the holeselective contact, slight intermixing between different layers seems to occur, which may partially result from a projection artefact linked to the small roughness of the $\mathrm{MoO}_{\mathrm{x}} / \mathrm{ITO}$ 
interface. For the electron-selective contact, a more distinct interface between the different layers is present, indicating no obvious intermixing. Moreover, a thin $\mathrm{SiO}_{\mathrm{x}}$ film is seen at both the $\mathrm{MoO}_{\mathrm{x}} / \mathrm{a}-\mathrm{Si}: \mathrm{H}(\mathrm{i})$ and $\mathrm{ZnO} / \mathrm{a}-\mathrm{Si}: \mathrm{H}(\mathrm{i})$ interfaces, but without obvious detrimental effect on device performance. Such interfacial reaction has been observed in the past ${ }^{38,39}$ and results from the higher affinity of $\mathrm{O}$ to $\mathrm{Si}$ compared to $\mathrm{Zn}$ or Mo.

\section{Conclusion}

In summary, the $\mathrm{ZnO}(75-\mathrm{nm}) / \mathrm{LiF}_{\mathrm{x}}(1.5-\mathrm{nm}) / \mathrm{Al}$ stack has been demonstrated as an efficient electron-selective contact with parasitic low infrared light absorption. The contact resistance from wafer to $\mathrm{Al}$ electrode is $0.136 \Omega \mathrm{cm}^{2}$, and a $F F$ of $79.2 \%$ and a $V_{\text {OC }}$ of $716 \mathrm{mV}$ are reached, clearly demonstrating its efficient electron-selective properties. This is found to stem at least partly from the low workfunction of the $\mathrm{LiF}_{\mathrm{x}} / \mathrm{Al}$ bilayer, despite the fact that the $\mathrm{ZnO}$ is as thick as $75 \mathrm{~nm}$. Through material characterization, we revealed that the $\mathrm{ZnO}$ is optically highly transparent for long wavelengths due to its low free carrier density. Increasing the thickness of the $\mathrm{ZnO}$ film can effectively decrease parasitic plasmonic light absorption within the rear metal electrode. As a result, the internal reflection and light absorption in the $\mathrm{Si}$ wafer increase, resulting in a higher $J_{\mathrm{SC}}$. Good electron selectivity is maintained for thicknesses up to $100 \mathrm{~nm}$. Therefore, efficient electron selectivity and good optical performance are simultaneously realized. As a proof-of-concept demonstration, we fabricated a c-Si solar cell by using ZnO (75 $\mathrm{nm}) / \mathrm{LiF}_{\mathrm{x}}(1.5 \mathrm{~nm}) / \mathrm{Al}$ as its electron-selective contact, $\mathrm{MoO}_{\mathrm{x}}(4 \mathrm{~nm})$ as HTL, while using a$\mathrm{Si}: \mathrm{H}(\mathrm{i})$ on both wafer sides as thin passivating interlayers. The PCE of the dopant-free hetero contact solar cell reaches $21.4 \%$, which is remarkable for such novel-concept c-Si solar cells with dopant-free contacts on both sides. The results shown here are expected to contribute to the development of high-efficiency silicon solar cells with simple fabrication methods. Also, our work may help in understanding and designing new carrier-selective, carrier-transport, or carrier-injection layers in other high performance photovoltaic or light-emitting diode devices.

\section{Methods}

For contact resistance measurement, n-type float zone (FZ) c-Si wafers were used as substrates. Their thickness was around $180 \mu \mathrm{m}$ and resistivity was about $2.1 \Omega \mathrm{cm}$. In the first group, both sides of a textured wafer were symmetrically covered with $(\sim 7 \mathrm{~nm})$ a-Si:H(i) and $(\sim 10 \mathrm{~nm}) \mathrm{n}$ a-Si:H films by plasma-enhanced chemical vapor deposition (PECVD), and further 
symmetrically capped with $(\sim 150 \mathrm{~nm})$ ITO and Ag by DC magnetron sputtering. With such structure, the contact resistance between c-Si(n) and a-Si:H(i)/a-Si:H(n)/ITO/Ag was obtained. In the other groups, one side of the textured wafers were covered with a-Si:H(i)/a$\mathrm{Si}: \mathrm{H}(\mathrm{n}) / \mathrm{ITO} / \mathrm{Ag}$, and the other sides were covered with $\mathrm{Al}, \mathrm{ZnO} / \mathrm{Al}, \mathrm{ZnO} / \mathrm{LiF}_{\mathrm{x}} / \mathrm{Al}, \mathrm{ZnO} / \mathrm{LiF}_{\mathrm{x}} / \mathrm{Au}$ or $\mathrm{ZnO} / \mathrm{LiF}_{\mathrm{x}} / \mathrm{Cu}$. Here, $\mathrm{ZnO}$ was deposited by LPCVD at $100{ }^{\circ} \mathrm{C}$ and its thickness was controlled to be $75 \mathrm{~nm}$. The thickness was estimated from measuring the thickness of $\mathrm{ZnO}$ on glass and then being divided by a morphology ratio of $1.5 . \mathrm{LiF}_{\mathrm{x}}, \mathrm{Al}, \mathrm{Au}$, and $\mathrm{Cu}$ were grown via thermal evaporation. The thickness of $\mathrm{LiF}_{\mathrm{x}}$ was $1.5 \mathrm{~nm}$. The dark $J-V$ curves of these structures were measured with Keithley 2601A source meter. Through subtracting the resistance within the $\mathrm{Si}$ wafer and the contact resistance between c-Si and a-Si:H(i)/a$\mathrm{Si}: \mathrm{H}(\mathrm{n}) / \mathrm{ITO} / \mathrm{Ag}$ from the resistance of the whole structures, the contact resistance between c$\mathrm{Si}$ and $\mathrm{Al}, \mathrm{ZnO} / \mathrm{Al}, \mathrm{ZnO} / \mathrm{LiF}_{\mathrm{x}} / \mathrm{Al}, \mathrm{ZnO} / \mathrm{LiF}_{\mathrm{x}} / \mathrm{Au}$ or $\mathrm{ZnO} / \mathrm{LiF}_{\mathrm{x}} / \mathrm{Cu}$ could be estimated.

For solar cell fabrication, the substrates were n-type FZ c-Si with a thickness of around 180 $\mu \mathrm{m}$ and resistivity of about $2.1 \Omega \mathrm{cm}$. The wafers were anisotropically etched to form surfaces featuring random pyramids. After cleaning the wafers and removing the native $\mathrm{SiO}_{\mathrm{x}}, \mathrm{a}-\mathrm{Si}: \mathrm{H}(\mathrm{i})$ film ( $7 \mathrm{~nm})$ was deposited on both sides as passivation layer via PECVD. Then the front sides (illumination side) were capped with either a-Si:H(p) $(\sim 10 \mathrm{~nm})$ via PECVD or $\mathrm{MoO}_{\mathrm{x}}(\sim 4 \mathrm{~nm})$ via thermal evaporation as hole-selective films. In the following, the front sides were further covered with a 75-nm-thick ITO film by magnetron sputtering with using a shadow mask to define $2 \mathrm{~cm} \times 2 \mathrm{~cm}$ area, and covered with $\mathrm{Ag}$ grids by screen printing, followed by curing at $210{ }^{\circ} \mathrm{C}$ (for hybrid cell) or $130{ }^{\circ} \mathrm{C}$ (for bifacial dopant-free-contact cell). Then the rear sides were coated with $\mathrm{ZnO}$ films by LPCVD at $100{ }^{\circ} \mathrm{C}$. Its thickness was controlled by deposition time. Subsequently, the samples were annealed at $150{ }^{\circ} \mathrm{C}$ for $30 \mathrm{mins}$ in the air atmosphere, and finally, the rear sides of the samples were capped with $1.5-\mathrm{nm}$-thick $\mathrm{LiF}_{\mathrm{x}}$ and $\mathrm{Al}$ via thermal evaporation.

Optical simulations: The optical simulation was carried out by wafer ray tracer calculator in PV Lighthouse to obtain the absorptance in the wafer, absorptance in the rear films and internal reflection. The simulated structure was the same as the experimental solar cell except that $\mathrm{LiF}_{\mathrm{x}}$ was not included. Optically, it is acceptable to neglect the $\mathrm{LiF}_{\mathrm{x}}$ film because it was only $1.5 \mathrm{~nm}$ in the solar cells. The LPCVD ZnO with low $k$ was used in the $\mathrm{ZnO}$ layer.

Material and device characterization: For all the following characterization, $\mathrm{ZnO}$ film was annealed at $150{ }^{\circ} \mathrm{C}$ for $30 \mathrm{mins}$ in air atmosphere as that for solar cells. For optical absorptance 
measurement, $\mathrm{ZnO}$ film was deposited on fused glass. Its reflectance and transmittance varying with wavelength were measured by a spectrophotometer (Lambda-950, Perkin Elmer). Absorptance was obtained through subtracting reflectance and transmittance from 1 . The carrier concentration of the $\mathrm{ZnO}$ film was obtained by Hall-effect measurements, which were performed on Lake Shore analyzer at room temperature dark conditions. Samples $\left(10 \times 10 \mathrm{~mm}^{2}\right)$ were prepared in Van der Pauw geometry on soda-lime glass substrates. The contacts for the electrical measurements were made by conductive silver paste. The ohmic behavior of the contacts was confirmed by the linear variation of the $I-V$ characteristics, which was observed to be independent of the polarity of the applied current and the contact combinations for each sample. Measurements were done under $10 \mathrm{kG}$ magnetic field. UPS measurements were performed in Kratos Axis Supra DLD spectrometer using a He I excitation ( $\mathrm{h} v=21.22 \mathrm{eV})$. A bias of $-9 \mathrm{~V}$ was applied to the sample surface for UPS measurements. Samples were mounted in contact mode for the UPS measurements. For spectroscopic ellipsometry measurement, the $\mathrm{ZnO}$ film was grown on a polished wafer. The measurement was taken on Unisel equipment of Horiba Jobin Yvon, and the fitting was done by combining Tauc-Lorentz, new amorphous and Drude models. The top view and cross-sectional view of the $\mathrm{ZnO}$ film coated on a textured $\mathrm{Si}$ wafer was characterized using a JEOL JSM-7500TFE SEM operated at $5 \mathrm{kV}$. For TEM characterization, all the films $\left(\mathrm{ZnO}, \mathrm{LiF}_{\mathrm{x}}, \mathrm{Al}, \mathrm{MoO}_{\mathrm{x}}, \mathrm{ITO}\right)$ were deposited on a polished $\mathrm{Si}$ wafer with $<111>$ orientation. The sample went through the same process as the solar cells, except that no Ag was printed on its front. The samples were prepared for TEM observations using the conventional focused ion beam lift-out method and thinned to their final thickness with a final gallium ion voltage of $2 \mathrm{kV}$ to reduce surface damage. The TEM samples were then transferred to an image and probe Cs-corrected FEI Titan Themis microscope equipped with 4 silicon drift detectors for fast EDX mapping. The microscope was operated at $200 \mathrm{kV}$ with a STEM beam current of $200 \mathrm{pA}$. The EQE of the solar cells was measured in an in-house built setup. $J-V$ characterization was performed using a Wacom WXS-90S-L2 solar simulator, at the standard test conditions (AM $1.5 \mathrm{G}, 100 \mathrm{~mW} / \mathrm{cm}^{2}$ and $25^{\circ} \mathrm{C}$ ).

\section{Acknowledgements}

The authors thank Vincent Paratte for amorphous silicon preparation and thank Christophe Allebé and Nicolas Badel from CSEM for the high-quality wet-processing and metallization. This project has received funding from the European Union's Horizon 2020 research and 
innovation program under Grant Agreement No. 727523 (NextBase), as well as Swiss national science foundation under Ambizione Energy grant ICONS (PZENP2_173627) and the China Postdoctoral Science Foundation. Part of this research reported in this publication was supported by funding from King Abdullah University of Science and Technology (KAUST) Office of Sponsored Research (OSR) under award no. OSR-CRG URF/1/3383, as well as funding from Saudi Aramco.

\section{Notes}

The authors declare no competing financial interest.

\section{Supporting information}

Supporting information associated with this article can be found in the online version.

\section{Reference:}

1 C. Battaglia, A. Cuevas and S. De Wolf, Energy Environ. Sci., 2016, 9, 1552-1576.

2 M. C. Raval and S. M. Reddy, in IntechOpen, 2019, DOI: 10.5772/intechopen.84817.

3 M. A. Green, Sol. Energy Mater. Sol. Cells, 2015, 143, 190-197.

4 S. C. Baker-Finch, K. R. McIntosh, D. Yan, K. C. Fong and T. C. Kho, J. Appl. Phys., 2014, 116, 063106.

5 F. Feldmann, M. Simon, M. Bivour, C. Reichel, M. Hermle and S. W. Glunz, Sol. Energy Mater. Sol. Cells, 2014, 131, 100-104.

6 J. Haschke, O. Dupré, M. Boccard and C. Ballif, Sol. Energy Mater. Sol. Cells, 2018, 187, 140-153.

7 Z. C. Holman, A. Descoeudres, L. Barraud, F. Z. Fernandez, J. P. Seif, S. De Wolf and C. Ballif, IEEE J. Photovoltaics, 2012, 2, 7-15.

8 J. Geissbühler, J. Werner, S. Martin De Nicolas, L. Barraud, A. Hessler-Wyser, M. Despeisse, S. Nicolay, A. Tomasi, B. Niesen, S. De Wolf and C. Ballif, Appl. Phys. Lett., 2015, 107, 081601.

9 J. Yu, Y. Fu, L. Zhu, Z. Yang, X. Yang, L. Ding, Y. Zeng, B. Yan, J. Tang, P. Gao and J. Ye, Sol. Energy, 2018, 159, 704-709.

10 X. Yang, Q. Bi, H. Ali, K. Davis, W. V. Schoenfeld and K. Weber, Adv. Mater., 2016, 28, 5891-5897.

11 X. Yang, E. Aydin, H. Xu, J. Kang, M. Hedhili, W. Liu, Y. Wan, J. Peng, C.

Samundsett, A. Cuevas and S. De Wolf, Adv. Energy Mater., 2018, 8, 1800608. 
12 X. Yang, W. Liu, M. De Bastiani, T. Allen, J. Kang, H. Xu, E. Aydin, L. Xu, Q. Bi, H. Dang, E. AlHabshi, K. Kotsovos, A. AlSaggaf, I. Gereige, Y. Wan, J. Peng, C. Samundsett, A. Cuevas and S. De Wolf, Joule, 2019. 3. 1314-1327.

13 Y. Wan, C. Samundsett, J. Bullock, T. Allen, M. Hettick, D. Yan, P. Zheng, X. Zhang, J. Cui, J. McKeon, A. Javey and A. Cuevas, ACS Appl. Mater. Interfaces, 2016, 8, 14671-14677.

14 J. Bullock, M. Hettick, J. Geissbühler, A. J. Ong, T. Allen, C. M. Sutter-Fella, T. Chen, H. Ota, E. W. Schaler, S. De Wolf, C. Ballif, A. Cuevas and A. Javey, Nat. Energy, 2016, 1, 15031.

15 J. Sheng, K. Fan, D. Wang, C. Han, J. Fang, P. Gao and J. Ye, ACS Appl. Mater. Interfaces, 2014, 6, 16027-16034.

16 T. Zhang, C. Y. Lee, Y. Wan, S. Lim and B. Hoex, J. Appl. Phys., 2018, 124, 073106.

17 M. Bivour, J. Temmler, H. Steinkemper and M. Hermle, Sol. Energy Mater. Sol. Cells, 2015, 142, 34-41.

18 C. Battaglia, X. Yin, M. Zheng, I. D. Sharp, T. Chen, S. McDonnell, A. Azcatl, C.

Carraro, B. Ma, R. Maboudian, R. M. Wallace and A. Javey, Nano Lett., 2014, 14, 967971.

19 R. Islam, P. Ramesh, J. H. Nam and K. C. Saraswat, in 2015 IEEE 42nd Photovoltaic Specialist Conference (PVSC), 2015, New Orleans, LA, USA.

20 M. Mews, A. Lemaire and L. Korte, IEEE J. Photovoltaics, 2017, 7, 1209-1215.

21 G. Masmitjà, L. G. Gerling, P. Ortega, J. Puigdollers, I. Martín, C. Voz and R. Alcubilla, J. Mater. Chem. A, 2017, 5, 9182-9189.

22 C. Battaglia, S. M. De Nicolás, S. De Wolf, X. Yin, M. Zheng, C. Ballif and A. Javey, Appl. Phys. Lett., 2014, 104, 113902.

23 J. Bullock, P. Zheng, Q. Jeangros, M. Tosun, M. Hettick, C. M. Sutter-Fella, Y. Wan, T. Allen, D. Yan, D. Macdonald, S. De Wolf, A. Hessler-Wyser, A. Cuevas and A. Javey, Adv. Energy Mater., 2016, 6, 1600241.

24 Y. Wan, C. Samundsett, J. Bullock, M. Hettick, T. Allen, D. Yan, J. Peng, Y. Wu, J. Cui, A. Javey and A. Cuevas, Adv. Energy Mater., 2017, 7, 1601863.

25 T. G. Allen, J. Bullock, Q. Jeangros, C. Samundsett, Y. Wan, J. Cui, A. Hessler-Wyser, S. De Wolf, A. Javey and A. Cuevas, Adv. Energy Mater., 2017, 7, 1602606.

26 X. Yang, K. Weber, Z. Hameiri and S. De Wolf, Prog. Photovoltaics Res. Appl., 2017, 25, 896-904.

27 Y. Wan, S. K. Karuturi, C. Samundsett, J. Bullock, M. Hettick, D. Yan, J. Peng, P. R. Narangari, S. Mokkapati, H. H. Tan, C. Jagadish, A. Javey and A. Cuevas, ACS Energy Lett., 2018, 3, 125-131.

28 Y. Wan, J. Bullock, M. Hettick, Z. Xu, C. Samundsett, D. Yan, J. Peng, J. Ye, A. Javey and A. Cuevas, Adv. Energy Mater., 2018, 8, 1800743.

29 Z. C. Holman, S. De Wolf and C. Ballif, Light Sci. Appl., 2013, 2, e106.

30 Z. C. Holman, M. Filipič, A. Descoeudres, S. De Wolf, F. Smole, M. Topič and C. 
Ballif, J. Appl. Phys., 2013, 113, 013107.

31 S. Zhong, M. Morales-Masis, M. Mews, L. Korte, Q. Jeangros, W. Wu, M. Boccard and C. Ballif, Sol. Energy Mater. Sol. Cells, 2019, 194, 67-73.

32 J. Yu, J. Bian, W. Duan, Y. Liu, J. Shi, F. Meng and Z. Liu, Sol. Energy Mater. Sol. Cells, 2016, 144, 359-363.

33 Z. C. Holman, M. Filipič, B. Lipovšek, S. De Wolf, F. Smole, M. Topič and C. Ballif, Sol. Energy Mater. Sol. Cells, 2014, 120, 426-430.

34 J. Y. Choi, K. Heo, K. S. Cho, S. W. Hwang, J. Chung, S. Kim, B. H. Lee and S. Y. Lee, Sci. Rep., 2017, 7, 15392.

35 J. Ding, Y. Zhou, G. Dong, M. Liu, D. Yu and F. Liu, Prog. Photovoltaics Res. Appl., 2018, 26, 974-980.

36 J. Bullock, Y. Wan, Z. Xu, S. Essig, M. Hettick, H. Wang, W. Ji, M. Boccard, A. Cuevas, C. Ballif and A. Javey, ACS Energy Lett., 2018, 3, 508-513.

37 F. Wang, S. Zhao, B. Liu, Y. Li, Q. Ren, R. Du, N. Wang, C. Wei, X. Chen, G. Wang, B. Yan, Y. Zhao and X. Zhang, Nano Energy, 2017, 39, 437-443.

38 L. G. Gerling, C. Voz, R. Alcubilla and J. Puigdollers, J. Mater. Res., 2017, 32, 260268.

39 D. Sacchetto, Q. Jeangros, G. Christmann, L. Barraud, A. Descoeudres, J. Geissbuhler, M. Despeisse, A. Hessler-Wyser, S. Nicolay and C. Ballif, IEEE J. Photovoltaics, 2017, 7, 1584-1590. 